\title{
A Review of Translational Animal Models for Knee Osteoarthritis
}

\author{
Martin H. Gregory, ${ }^{1}$ Nicholas Capito, ${ }^{2}$ Keiichi Kuroki, ${ }^{3}$ Aaron M. Stoker, ${ }^{3}$ \\ James L. Cook, ${ }^{3}$ and Seth L. Sherman ${ }^{2}$ \\ ${ }^{1}$ School of Medicine, University of Missouri, Columbia, MO, USA \\ ${ }^{2}$ Missouri Orthopaedic Institute, 1100 Virginia Avenue, DC 953.00, Columbia, MO 65212, USA \\ ${ }^{3}$ Comparative Orthopaedic Laboratory, College of Veterinary Medicine, University of Missouri, Columbia, MO, USA
}

Correspondence should be addressed to Seth L.Sherman, shermanse@health.missouri.edu

Received 10 August 2012; Revised 8 November 2012; Accepted 26 November 2012

Academic Editor: Paola Migliorini

Copyright ( $) 2012$ Martin H. Gregory et al. This is an open access article distributed under the Creative Commons Attribution License, which permits unrestricted use, distribution, and reproduction in any medium, provided the original work is properly cited.

Knee osteoarthritis remains a tremendous public health concern, both in terms of health-related quality of life and financial burden of disease. Translational research is a critical step towards understanding and mitigating the long-term effects of this disease process. Animal models provide practical and clinically relevant ways to study both the natural history and response to treatment of knee osteoarthritis. Many factors including size, cost, and method of inducing osteoarthritis are important considerations for choosing an appropriate animal model. Smaller animals are useful because of their ease of use and cost, while larger animals are advantageous because of their anatomical similarity to humans. This evidence-based review will compare and contrast several different animal models for knee osteoarthritis. Our goal is to inform the clinician about current research models, in order to facilitate the transfer of knowledge from the "bench" to the "bedside."

\section{Introduction}

Knee osteoarthritis (OA) affects an estimated 27 million Americans [1]. Despite extensive research seeking therapeutic interventions for this disease, there are still no proven disease-modifying treatments for osteoarthritis. With the number of total knee arthroplasties growing each year, this is a rapidly expanding public health epidemic, both in terms of health-related quality of life and financial expenditure [2]. The major hurdles in osteoarthritis research include elucidating the mechanisms of disease, determining methods for early detection, and developing strategies for intervention and disease modification. Translational research is a critical step towards understanding and mitigating the long-term effects of this disease process. Animal models provide practical and clinically relevant ways to study both the natural history and response to treatment of knee osteoarthritis. A translational animal model is one that facilitates the translation of findings from basic science to practical applications that enhance human health and well-being. The other types of animal models would include veterinary clinical (an animal model of an animal disease), comparative, discovery, and mechanistic, among others. This evidence-based review will compare and contrast several different animal models for knee (stifle) osteoarthritis. Our goal is to provide an outline of the factors that are important in choosing an appropriate animal model and to provide illustrative examples that demonstrate how each animal model has aided our understanding of OA. The OARSI histopathology initiative brought together experts in OA research to develop a scoring system to facilitate comparison of results across species [7481]. The reports reviewed anatomy and histology of each animal model. We relied on these excellent reports, as well as several other review articles [82-84], to identify relevant animal models and identify areas that our review could improve upon existing work. Separate PubMed literature searches were conducted using the terms "osteoarthritis OR osteoarthrosis" and "knee OR femur OR tibia" along with "mouse," "rat," "rabbit," "guinea pig," "dog," "sheep," "goat," and "horse." Only in vivo models studie were considered. Articles were selected after a review by our multidisciplinary team of orthopedic surgeons, veterinary surgeons, and Ph.Ds. Selected articles had particular relevance to human 
osteoarthritis, novel findings, and ability to serve as illustrative examples of the strengths and weaknesses of a specific animal model. Admittedly, plenty of excellent articles were not included in our review. Our goal, however, was not to provide an exhaustive list of every work published on translational OA research. Our purpose was to highlight the best examples in the literature to aid the clinician/scientist in choosing an animal model for a specific research question. Our goal is to inform the clinician about current research models, in order to facilitate the transfer of knowledge from the "bench" to the "bedside."

\section{Factors in Determining an Appropriate Animal Model}

Unfortunately, there is no single gold standard animal model for knee osteoarthritis. Each animal model has unique advantages and disadvantages (Table 1). As such, it is critically important to understand the clinically relevant question under investigation and the hypothesis being tested, in order to choose an appropriate model. For example, if one wanted to study the natural history of knee osteoarthritis, a rat model would be inappropriate since this does not typically occur in wild-type rats [85]. In contrast, dogs or horses would be appropriate selections for this experimental design, as these animals share similar risk of knee osteoarthritis secondary to trauma, meniscal tears, osteochondrosis, and aging as their human counterparts $[86,87]$.

The method of osteoarthritis induction is another important consideration. While surgical anterior (cranial) cruciate ligament (ACL) transection has been the most commonly used animal model for osteoarthritis, particularly in dogs, it may not be the most applicable to human OA. In comparison to human knee OA, ACL transection is associated with immediate and severe joint instability that results in extended periods of complete lack of weightbearing on the affected limb $[47,48,58]$. In contrast, human knee OA tends to develop more insidiously, sometimes without evidence of prior injury $[88,89]$. Another major criticism with respect to applicability of the ACL transection model involves the high degree of variability noted in outcome measures typically employed [49-51, 90-92]. In dogs, level of function, diagnostic imaging findings, presence and severity of meniscal pathology, and arthroscopic, gross, and histologic measures of articular cartilage damage could be variable among animals after ACL transection [49-51, 92, 93]. This results in a requirement for higher numbers of animals to be included in order to adequately power the study and appropriately apply the data to the human clinical situation. As such, costs increase greatly and use of research animals is not minimized as desired. Therefore, models of OA that more closely mimic human knee OA have been developed and tested [48, 57-60, 94]. Surgical creation of articular surface lesions or meniscal deficiency of various types as described below currently provide the most consistent and least variable models of human knee OA $[48,57-60,94]$.

Age, size, and gender/reproductive statuses of the animals also have important influences on study design and data application [95-97]. It is generally preferable to use skeletally mature animals for $\mathrm{OA}$ models in order to minimize the effects of intrinsic healing and regenerative capacity such that data are more applicable to humans [84]. In general, small animals (mice, rats, rabbits, and guinea pigs) are most advantageous in terms of costs, housing, genetic manipulation, and public perception, whereas large animals (dogs, goats, sheep, pigs, and horses) are most advantageous in terms of anatomical and biomechanical similarities to humans, ability to use routine diagnostic imaging, capabilities for arthroscopic interventions, and postoperative management with respect to $\mathrm{OA}$ research. As such, small animal models of OA are primarily used for investigating specific disease mechanisms or initial screening of therapeutics while large animal models provide more clinically relevant data and are typically required for FDA approval of diagnostics, biologics, and devices. Gender/reproductive status may also play roles in OA research in terms of hormonal influences on physiology, response to treatments, and various side effects [95]. All of these factors have direct impact on financial costs of OA research. Animal-related costs encompass not only the acquisition of research animals, but also housing of animals and salaries of personnel involved in animal care and assessments.

Noninvasive outcome measures of disease progression are particularly important in OA research because humans remain asymptomatic until relatively late in the disease process. Many treatments that have shown promise in animal models produce disappointing results in humans because treatments are started so late in the disease course $[98,99]$. Matrix metalloproteinase inhibitors reduced cartilage degradation in rats [16], guinea pigs [23], and dogs [100]. In a human clinical trial, however, a matrix metalloproteinase inhibitor failed to reduce joint space narrowing and led to significant musculoskeletal adverse effects [98]. Similarly, bisphosphonates reduce cartilage degradation in rats [12] and rabbits [21], but failed to reduce symptoms or joint space narrowing in humans [99]. There is hope that earlier detection of knee OA may allow for treatments designed to halt or even reverse disease progression. Biomarkers and magnetic resonance imaging are two areas of active research that will be discussed in detail in later sections. MRI allows noninvasive assessment of objective outcomes such as cartilage volume that can also be measured in humans [101-103]. In humans, MRI can assess cartilage volume, bone marrow lesions, ligamentous and meniscal pathology, and synovial fluid volume and synovitis $[101,102]$. Several recent clinical trials used parameters assessed by MRI as outcome variables [104-106]. Dogs, goats, and horses can be imaged effectively using 1.5 and 3T clinical magnets with routine coils and sequencing [92, 93, 103, 107, 108]. Mice, rabbits, and guinea pigs are too small to undergo routine MRI in vivo $[18,24,25$, 109 ], and only recently has the feasibility of micro-MRI been demonstrated in rats [110].

Finally, the public has become increasingly concerned about the humane treatment of animals. Dogs in particular have a special connection to humans and their use in medical research has drawn the scrutiny of many people. The Animal Welfare and Horse Protection Acts was an essential step in 
TABLE 1: Advantages and disadvantages of osteoarthritis animal models.

\begin{tabular}{|c|c|c|c|}
\hline & Advantages & Disadvantages & Models used \\
\hline Mouse & $\begin{array}{l}\text { Low cost } \\
\text { Easy of use } \\
\text { Genome sequenced } \\
\text { Can view hole knee can on slides }\end{array}$ & $\begin{array}{l}\text { Thin cartilage } \\
\text { Postoperative management difficult }\end{array}$ & $\begin{array}{l}\text { Genetic [3-7] } \\
\text { Meniscal destabilization [7] } \\
\text { Chemical [7] }\end{array}$ \\
\hline Rat & $\begin{array}{l}\text { Low cost } \\
\text { Ease to use } \\
\text { Thicker cartilage than mouse } \\
\text { Can view hole knee can on slides }\end{array}$ & $\begin{array}{l}\text { Small joints } \\
\text { Postoperative management difficult }\end{array}$ & $\begin{array}{l}\text { Medial meniscus tear }[8-10] \\
\text { Partial medial meniscectomy [11] } \\
\text { ACL transection }[12-14] \\
\text { ACL transection with partial medial } \\
\text { meniscectomy }[13,15] \\
\text { Chemical }[16,17]\end{array}$ \\
\hline Rabbit & Easy to use & $\begin{array}{l}\text { Knee biomechanics } \\
\text { Cartilage capable of regeneration } \\
\text { Different histology from human } \\
\text { Postoperative management difficult }\end{array}$ & $\begin{array}{l}\text { ACL transection }[18,19] \\
\text { Meniscectomy }[20] \\
\text { Chemical }[21,22]\end{array}$ \\
\hline Guinea pig & $\begin{array}{l}\text { Similar histopathology to human } \\
\text { Prone to spontaneous OA }\end{array}$ & $\begin{array}{l}\text { Sedentary lifestyle } \\
\text { Arthroscopy not possible }\end{array}$ & $\begin{array}{l}\text { Spontaneous }[23-42] \\
\text { Meniscectomy }[43] \\
\text { Chemical }[44,45]\end{array}$ \\
\hline Dog & $\begin{array}{l}\text { Prone to spontaneous OA } \\
\text { Arthroscopy feasible } \\
\text { MRI feasible } \\
\text { GI physiology } \\
\text { Genome sequenced } \\
\text { Validated outcome measures }\end{array}$ & $\begin{array}{l}\text { Cost } \\
\text { Public perception }\end{array}$ & $\begin{array}{l}\text { Spontaneous }[46] \\
\text { ACL transection }[46-56] \\
\text { Meniscal release }[48,57] \\
\text { Focal cartilage defect }[48,58-60]\end{array}$ \\
\hline Sheep/goat & $\begin{array}{l}\text { Large joint } \\
\text { Easy to use } \\
\text { Arthroscopy feasible } \\
\text { MRI feasible }\end{array}$ & $\begin{array}{l}\text { Cost } \\
\text { GI physiology }\end{array}$ & Partial/total meniscectomy [61-66] \\
\hline Horse & $\begin{array}{l}\text { Spontaneous OA } \\
\text { Can induce OA without instability } \\
\text { Arthroscopy feasible } \\
\text { MRI feasible }\end{array}$ & $\begin{array}{l}\text { Cost } \\
\text { Anatomy }\end{array}$ & $\begin{array}{l}\text { Spontaneous }[67] \\
\text { Osteochondral-fragment exercise model } \\
{[68-73]}\end{array}$ \\
\hline
\end{tabular}

assuring that research animals are treated humanely. The study must be carefully designed to use as few animals as possible to answer a particular research question. This involves undertaking power analyses prior to using an animal model. In addition, investigators are committed to searching for ways to minimize the use of animals by adopting alternative methods when available. All animal research must be described in an Animal Care and Use Committee (ACUC) Protocol Form, which must be approved by the institutional ACUC prior any animal work being performed.

\section{Mouse}

Due to its ease of use and low cost, mouse models have served as the foundation of biomedical animal models for a long time [111]. In osteoarthritis research, however, where load and biomechanics are deemed important contributing factors, the mouse knee is problematic because of its extremely small size compared to humans [77]. Mouse knee cartilage is very thin, lacking discernible radial, transitional, and superficial layers $[77,112]$. Humans and other large animals have a thin layer of calcified cartilage adjacent to the subchondral bone, whereas in mice this layer makes up a greater share of the cartilage thickness [77]. This thin cartilage makes it difficult to induce small defects that progress slowly to OA [77]. One advantage of the small joint is that slides can be made that capture an entire slice of the joint. In addition to transgenic models described below, meniscal destabilization is used to induce osteoarthritis [113]. Postoperative management is difficult with such a small animal. Functional assessments, exercise regimens, and splinting are difficult or impossible to do. Mice are too small to undergo routine MRI, but micro-MRI can be used [109].

Despite these limitations, mouse models have proved useful in elucidating the genetic and molecular pathogenesis of OA. The entire mouse genome has been sequenced and knockout mice have been used extensively to study genotypephenotype relationships in OA. Since most cases of OA are likely to be caused by many different alleles each conferring a small amount of risk, mouse models were initially useful in studying rare monogenic disorders with OA as part of the phenotype [3-5]. For example, Kniest and Sickler syndromes were found to be associated with defects in collagen type II gene (COLA21) [3]. Mouse models showed that internal COLA21 deletion led to a range of phenotypes that encompass Kniest and Sickler syndromes [6]. Mice with milder 
phenotypes developed significant OA as they got older. These and other studies helped to illuminate the essential role of structural proteins in skeletal development and degenerative diseases such as OA.

More recently, mouse models have provided a means to study candidate genes found in large genomic association studies in humans. Several studies have found an association between a single-nucleotide polymorphism in the $5^{\prime}$-UTR of the growth and differentiation factor 5 (GDF5) gene and risk of OA [114-116]. Daans et al. used a transgenic mouse with a mutated GDF5 allele ( $G d f 5^{B p-J /+}$ ) to study susceptibility to OA [7]. They evaluated the development of OA using 4 models: (1) injected collagenase; (2) injected papain; (3) meniscal destabilization; and (4) exercise induced. In the collagenase model, the contralateral limbs of $G d f 5^{B p-J /+}$ mice had more OA-like changes compared to wild type (WT). The authors hypothesized that the collagenase injection led to increased loading in the contralateral limb and that $G d f 5^{B p-J /+}$ mice were more susceptible to damage from this increased load than WT mice. The running model was associated with increased synovial hypertrophy, but the papain and meniscal models did not show any difference in degenerative changes [7].

\section{Rat}

Rats offer similar advantages and disadvantages to the mouse. They are inexpensive and easy to care for. Rats have an advantage over mice in that their cartilage is thick enough to induce both partial and full-thickness cartilage defects [76, $117,118]$. This has allowed the rat to be used for the study of cartilage restoration techniques such as gene therapy [117], stem cell transplantation [118], and growth factor treatments [119]. Although larger than mice, rat joints are still extremely small compared to larger animals and humans. In contrast to mice, genetically engineered rats are not currently available. As in mice, postoperative management is difficult. Rats cannot undergo routine MRI, but recently the feasibility of micro-MRI has been demonstrated [110]. Methods to induce OA in rats include medial meniscus tear [8-10], ACL tear [12-14], partial medial meniscectomy [11], ACL tear with partial medial meniscus tear $[13,15]$, and iodoacetate injection $[16,17]$.

Rat models have been used to extensively characterize OA-related pain and evaluate treatments. Bove et al. transected the medial meniscus and MCL to characterize the pain profile of OA in rats [9]. Rats with induced OA had increased joint pain and tactile allodynia. The authors argued that this mimicked the nociceptive and neuropathic aspects of OArelated pain in humans, and thus the rat could be used as a model to study pain treatments. Fernihough et al. compared the pain profile in a partial medial meniscectomy model and iodoacetate model [10]. Both produced significant mechanical hyperalgesia and tactile allodynia, although the iodoacetate model produced more pain. The iodoacetate model has been used most often to study pain in rat models. Novel pain therapies have been tested using rat models of $\mathrm{OA}$, including a histamine $\mathrm{H} 3$ receptor antagonist [120], an endocannabinoid hydrolysis inhibitor [26], and proteasome inhibitor [121].

\section{Rabbit}

The rabbit knee is similar in gross appearance to the human knee except for a smaller patella relative to other structures [79]. The rabbit knee, however, is kept in a higher degree of flexion and the gait is vastly different from humans and other animals [79]. Thus, the biomechanics are very different. Histologically, the rabbit is different also. The rabbit meniscus has greater cellularity than human meniscus as well as less vascular penetration [122]. Rabbits lack a lamellar collagen layer at the articulating surfaces that is present in humans and sheep [122]. A major problem in using the rabbit model is rabbit articular cartilage that is capable of regeneration, which may be due to the fact that rabbits up to 8 months of age can have open physes on growth plates in the distal femur and proximal tibia $[123,124]$. Rabbit models of OA include ACL tear, $[18,19]$ meniscectomy $[20]$ and chemically induced $[21,22]$. Similar to mice and rats, postoperative management is difficult. Micro-MRI is required for rabbit imaging, although some lesions can be seen with routine MRI $[18,125]$.

Despite its limitations, the rabbit model has been used to evaluate the efficacy of various compounds. It has allowed mechanisms of efficacy to be studied in ways that would be impossible in humans. Various types of hyaluronic acid have been tested. High molecular weight hyaluronic acid was shown to be superior to lower MW [126], and cross-linked hyaluronic acid was superior to other compositions [127]. It was shown to reduce apoptosis and nitric oxide production, with the results being more pronounced earlier in the disease process [19]. Hyaluronic acid reduced expression of IL- $1 \beta$ and matrix metalloproteinase-3 (MMP-3) in the synovium but not in cartilage [128]. Zhang et al. recently demonstrated the efficacy of intra-articular injections of the antitumor necrosis factor antibody infliximab in a rabbit model where the ACL and medial menisci were transected [129]. Other compounds including caspase inhibitors [130], chitinous materials [131, 132], resveratrol [133], and bisphosphonates $[134,135]$ have also been studied.

\section{Guinea Pig}

The guinea pig knee is similar to the human knee, but much smaller. Bone growth stops by 4 months of age, but growth plate fusion occurs several months later [78]. The guinea pig has varus alignment of the stifles (knees), which puts increased load on medial compartment [78]. It follows that the medial compartment in guinea pigs develops OA first $[27,136]$. The central portion of medial compartment is not covered by meniscus, making it more susceptible to OA [136].

There are two major advantages of the guinea pig as a translational model. First, the histopathology is remarkably similar to human OA $[78,137]$. Second, spontaneous OAprone animals are available (Figure 1). The Dunkin-Hartley 


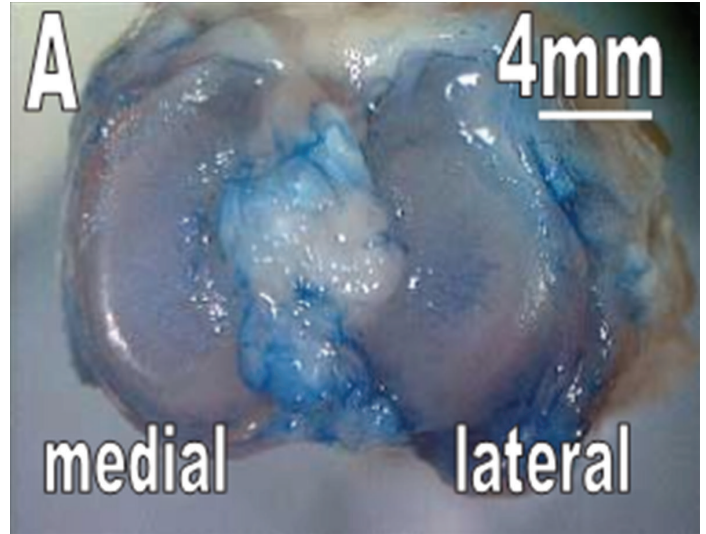

(a)

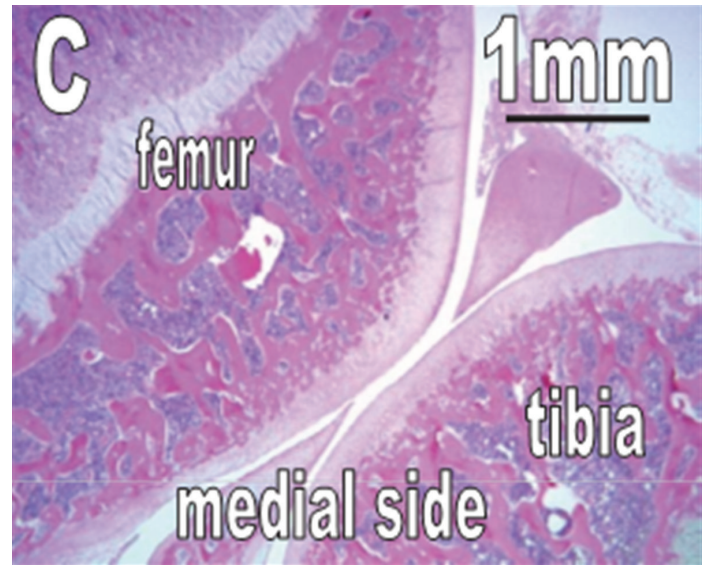

(c)

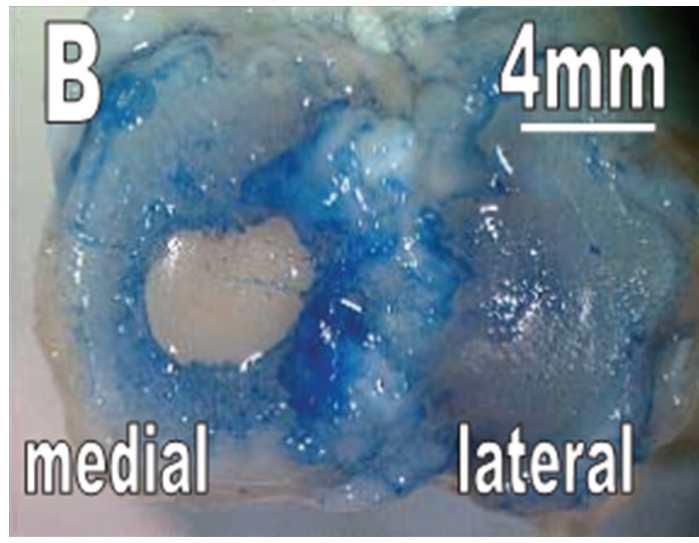

(b)

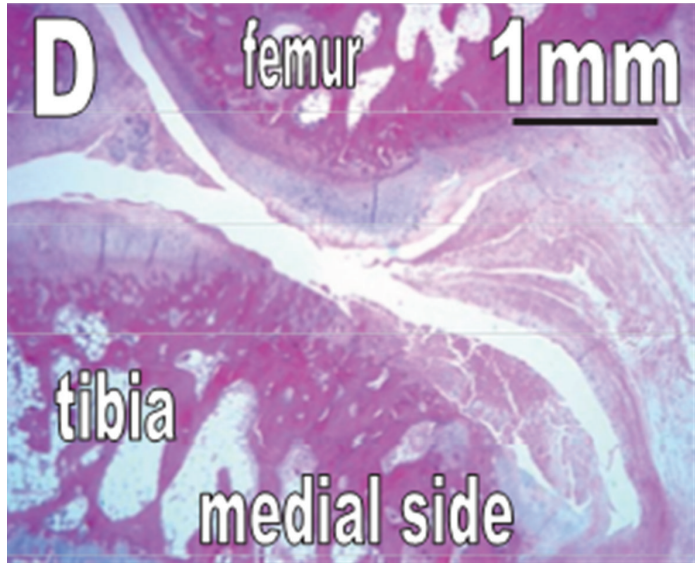

(d)

Figure 1: Macroscopic observation and histology of the tibial cartilage of a 3-month-old (a, c) and 12-month-old (b, d) Dunkin Hartley guinea pigs. No cartilage degeneration is observable at 3 months. In contrast, at 12 months, the cartilage is degenerated with erosion and fragmentation on the medial side. Reprinted with permission from [25].

strain [27] is the most commonly used, but there are other lesser known strains such as strain $13[28,29]$ and GOHI models [30]. These strains develop OA slower than the Dunkin-Hartley model and thus provide a useful comparison for temporal patterns of OA development $[29,30]$. The much shorter time to skeletal maturity is an advantage over other spontaneous OA models such as the dog and horse. In addition, the guinea pig's docile nature makes it easy to use. A disadvantage is that while the sedentary lifestyle of the guinea pig makes it easier to care for, it is not ideal for studying the role of exercise in OA.

Much of the OA research has utilized the Hartley strain, although other models have been used, namely, medial meniscectomy [43] and chemically induced by iodoacetate [44] and papain [45]. The spontaneous OA model has allowed characterization of the natural history of OA grossly, histologically, and biochemically. Type II collagen, normally found in attachment sites of tendons and ligaments, is deposited in central portion of the posterior cruciate ligament prior to development of OA [31]. The medial meniscus ossifies in the development of OA and correlates with the severity of lesions $[32,33]$. Wei et al. found an increase in proteoglycan (PG) and collagen prior to OA being seen, then a reduction in PG and collagen content with an increase in water content after OA was established [34]. This suggests articular cartilage is able to respond to increased stress up to a certain threshold and then breaks down leading to OA. Alterations in proteoglycan-collagen interactions precede changes in the articular surface [35]. MRI has been used in guinea pigs to characterize the progression of spontaneous OA [24, 25, 36-38].

Advanced age and body mass index (BMI) are risk factors for OA in humans, and guinea pig models have allowed these risk factors to be studied more in depth. Bendele and Hulman demonstrated the importance of BMI by showing that diet reduction reduced the severity of OA lesions [96]. Hyttinen et al. found that alterations in collagen structure in response to exercise differed in young and old guinea pigs [97].

The spontaneous OA model is an advantage over injuryinduced models because it allows study of prophylactic therapy, such as matrix metalloproteinase inhibitors [23] and glucosamine and chondroitin sulfate [39]. Additionally, the Hartley model is useful to study pain from OA, since 

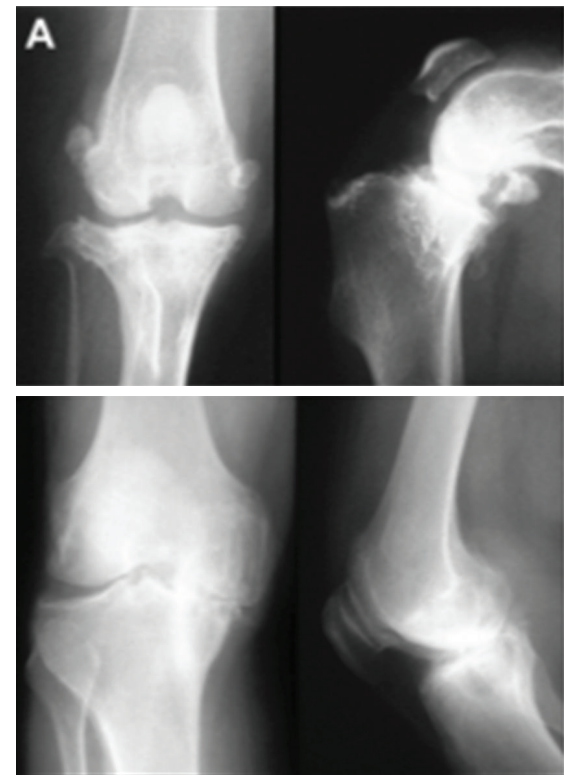

(a)
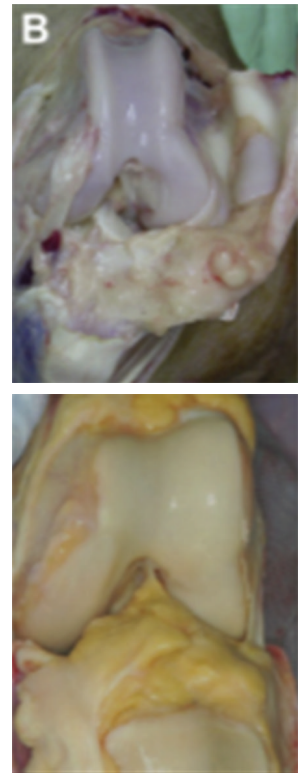

(b)
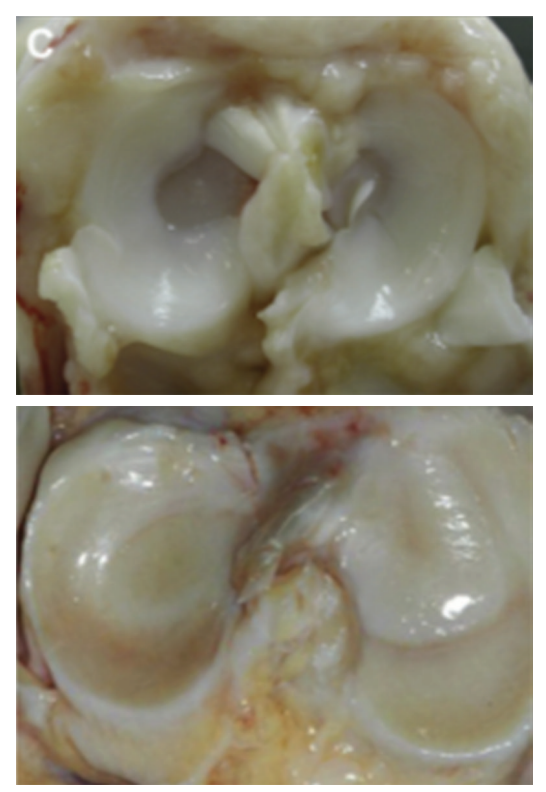

(c)

FIGURE 2: Comparative radiographic (a) and gross (b, c) anatomy of the canine stifle (top row) and human knee (bottom row). The radiographic images show osteoarthritic joints while the gross images show normal patellofemoral joints (b) and normal tibial plateaus (c). The canine stifle joint is approximately $3.5-5 \mathrm{~cm}$ from medial to lateral edge for medium to large breed dogs (upper left panel a) compared to approximately $7-10 \mathrm{~cm}$ for the human knee joint (lower left panel a) reprinted with permission from [75].

the surgery itself may cause pain in induced models of OA. Endocannabinoid hydrolysis inhibitors have recently been tested in guinea pig models [26]. The feasibility of newer therapies such as RNA interference [40], gene therapy [41], and human mesenchymal stem cells [42] has also been evaluated in guinea pig models.

\section{Canine}

The canine model is probably the closest to a gold-standard animal model for OA currently available. The canine stifle (knee) joint is remarkably similar to the human knee (Figure 2) [75]. The only major differences are sesamoid bones in the popliteus and lateral and medial heads of the gastrocnemius muscles, and the long digital extensor tendon that crosses the intra-articular anterolateral compartment [75]. Dogs are large enough to undergo arthroscopy and MRI. MRI can detect early signs of OA in dogs $[92,103]$ and is more sensitive than radiography at tracking progression of OA after ACL transection $[92,93,103]$. Dogs are by far the easiest to control postoperatively. They tolerate splinting better than other animals and are able to undergo exercise regimens, including water training. Furthermore, since canine models are commonly used, there are a wealth of data and many validated outcome measures that allow comparison across studies. Examples are the Canine Brief Pain Inventory [138] and force plate gait analysis [139]. Like the mouse, the canine genome has been sequenced [140].

The major disadvantages of the canine model relate to cost and public perception. Dogs are relatively expensive particularly if bred for research purposes. Housing requirements are more costly compared to smaller animals, including daily walking requirements. Humans have a special connection to dogs, and this has stirred strong opposition to the use of dogs in research.

The first canine model was developed several decades ago by Pond and Nuki [47]. They transected the ACL in dogs and found radiographic and histologic features of OA. Since then the Pond-Nuki model has been used extensively [48-55, 59, $100]$. Other canine models include meniscectomy or meniscal release [48, 57], creation of a focal defect $[48,58-60]$, or chemical induction [141, 142]. In addition, dogs develop spontaneous osteoarthritis [86]. Osteoarthritis is common for veterinarians to see, with an estimated $20 \%$ of dogs older than one year of age affected [143]. Dogs undergo similar treatments as humans, such as oral therapy, intra-articular hyaluronic acid injections, arthroscopic surgery, and knee replacement $[144,145]$. As with the guinea pig, this is a tremendous advantage over other animals because it enables study of the natural progression of the disease.

Having multiple models at the researcher's tool kit allows examination of subtle differences in the pathology associated with different causes of OA. Kuroki et al. examined the subchondral bone changes in ACL transection, medial femoral condylar groove creation, and meniscal release compared to sham surgery [48]. ACL transection led to considerably more cartilage damage, functional loss, and thinnest trabecular bone. Liu et al. found that proteoglycan levels differed in ACL and spontaneous OA models [52]. Notably, aggrecan content decreased in spontaneous OA, but increased after ACL transection. Marijnissen et al. found that a groove model led to greater cartilage damage but less 
synovial inflammation compared to an ACL model [59]. These results show that OA progression can be varied by the type of insults and the method of inducing OA needs to be carefully considered and generalization of results to humans should be done cautiously.

Another advantage of canine models is their similar gastrointestinal physiology to humans, which facilitates the study of enteral therapies. Licofelone, a novel drug that inhibits cyclooxygenase and 5-lipoxygenase, illustrates the use of dogs as a translational model. Its efficacy was demonstrated by reducing the size of cartilage lesions after ACL transection in dogs [53]. Using a canine model allowed more detailed analysis of the effects on the knee joint, including its effects on cartilage, subchondral bone, and the synovium. It reduced expression of matrix metalloproteinase 13 (MMP13), cathepsin K, and aggrecanases in cartilage [54]. It attenuated subchondral bone loss, which also showed reduced expression of MMP-13 and cathepsin K [55]. It reduced the size of villous hyperplasia in the synovium and synthesis of collagenase 1 and IL-1 $\beta$ [53].

One of the concerns about the "translatability" of animal models is that the benefit of treatments may be greater in animals because treatment is initiated at the time the injury is induced, before the development of OA. Humans are treated much later on in the disease process. While the ideal way to address this would probably be to take advantage of the canine's tendency to develop spontaneous OA, Moreau et al. attempted to address it by delaying licofelone until 4 weeks after ACL transection, showing that licofelone was still effective [56]. Licofelone has recently been studied in humans and has shown potential as a disease-modifying agent [104].

A recent study by Garner et al. illustrates the advantages of the canine as a translational model [46]. Previous studies with cartilage explants found increased metalloproteinase expression in OA patients compared to normal patients [146, 147]. Another study found differential chemokine expression in OA patients [148]. In particular, monocyte chemoattractant protein 1 (MCP1) was elevated compared to normal. Garner et al. simultaneously examined 3 different induction methods of $\mathrm{OA}$ as well as spontaneous $\mathrm{OA}$ to identify potential biomarkers of OA [46]. They used arthroscopy to induce OA by ACL transection, meniscal release, and groove creation, with another group of dogs undergoing a sham operation (Figure 3). The second part of the study examined dogs presenting to a veterinarian for surgical treatment of OA. A group of dogs without evidence of OA was used as a control. They tracked a variety of potential markers, including various matrix metalloproteinases and cytokines. They found that MCP-1 and IL- 8 were elevated in the synovial fluid in all of the induced OA models and spontaneous OA. Each exhibited high sensitivity and specificity for detecting OA [46]. The results need to be applied to humans, but the success of the biomarkers in differentiating OA from normal in induced OA and spontaneous OA is a promising development in the search for OA biomarkers.

\section{Goats and Sheep}

There are several characteristics of goats and sheep that facilitate their use as translational models. Their knee joints are closer in size to humans compared to dogs and smaller animals [80]. Thus, arthroscopy and MRI are feasible [107, 149]. Goats and sheep are fairly easy to use, as they are generally not aggressive. The gross anatomy of the joint is similar to humans, except a long digital extensor tendon crosses within the joint in the anterolateral compartment [80].

One disadvantage in using goats and sheep for OA models is that they are not prone to spontaneous arthritis. Surgical partial or complete meniscectomy is generally used to induce OA, as ACL transection causes only limited cartilage damage in the goat [150]. This is in contrast to canines, where ACL transection causes significantly more damage than meniscal release or groove creation [48]. Another disadvantage is that goats and sheep are ruminant rather than monogastric, which is not ideal for studying enteral therapies.

Sheep and goat models have been useful in exploring the effects of meniscal pathology in relation to OA. BylskiAustrow et al. showed that meniscectomy leads to a significant increase in joint pressure, but that the joint pressure decreased over time [61]. Others have shown that exercise exacerbates osteoarthritic changes in sheep without menisci $[62,63]$. Beveridge et al. conducted a detailed analysis of the kinematics of the sheep stifle (knee) following lateral meniscectomy [64]. The minimum tibiofemoral distance shifted laterally, leading to more cartilage damage in that area. More recently, techniques for replacing the meniscus have been explored using ovine models. Kelly et al. demonstrated the chondroprotective effects of meniscal allograft transplantation in a sheep model [65]. Murphy et al. found that intraarticular injection of mesenchymal stem cells suspended in hyaluronan led to some regeneration of excised meniscus and slowing of OA progression [66].

Ovine models have also been used to study novel therapies to repair cartilage defects. Heiligenstein et al. demonstrated that genetically modified chondrocytes implanted into ovine cartilage defects expressed genes for 21 days [151]. Marquass et al. successfully implanted predifferentiated mesenchymal stem cells that remained free of degradation after one year [152]. They compared these results to implantation of chondrocytes and found favorable results. A novel technique for autologous chondrocyte transplantation in a single procedure showed success up to 6 months in a goat model [153].

\section{Horse}

The front "knee" of the horse is actually analogous to the human wrist with two layers of carpal bones. The metacarpophalangeal joint, involving the large canon bone (third metacarpal) and the first phalanx, is most susceptible to spontaneous osteoarthritis [81]. The most commonly used osteochondral fragment-exercise model involves creating fragments in the middle carpal joint [68]. An advantage of this model is that no instability is created, but the cartilage is thinner compared to human knee cartilage [81].

Horses are unique in that they are not solely "translational" models, having long been known to suffer from spontaneous OA [87]. The lucrative horse racing industry 
TABLE 2: Summary of contributions to osteoarthritis knowledge.

\begin{tabular}{ll}
\hline Mouse & $\begin{array}{l}\text { Mutations in structural proteins can lead to OA [6]. Single-nucleotide polymorphism associated with increased risk in } \\
\text { human populations leads to increased OA in a mouse model [7]. }\end{array}$ \\
\hline Rat & $\begin{array}{l}\text { Novel therapies shown to reduce pain [26, 120, 121]. Feasibility of new cartilage restoration techniques demonstrated } \\
{[117-119] .}\end{array}$ \\
\hline \multirow{2}{*}{ Rabbit } & $\begin{array}{l}\text { Hyaluronic acid (HA) more effective earlier in disease process [19]. HA reduces inflammatory cytokine and } \\
\text { metalloproteinase expression in synovium but not cartilage [128]. High molecular weight hyaluronic acid superior to } \\
\text { low MW [126]. Infliximab may be efficacious in OA [129]. }\end{array}$ \\
\hline \multirow{3}{*}{ Guinea pig } & $\begin{array}{l}\text { Structural alterations occur in the meniscus and posterior cruciate ligament (PCL) prior to development of OA [31-33]. } \\
\text { Collagen and proteoglycan content increases prior to development of OA and then decreases once OA is evident [34]. } \\
\text { Diet reduction reduces severity of OA lesions [96]. }\end{array}$ \\
\hline \multirow{2}{*}{ Dog } & $\begin{array}{l}\text { OA progression differs based on inciting event [48, 52, 59]. ACL transection leads to severe damage compared to } \\
\text { meniscal release and groove creation [48]. Oral therapy reduces metalloproteinase expression in the joint and reduces } \\
\text { cartilage lesions [53-55]. Biomarkers in synovial fluid had high sensitivity and specificity in diagnosing OA [46]. }\end{array}$ \\
\hline Sheep/goat & $\begin{array}{l}\text { Knee joint remodels to reduce acute increase in joint pressure from meniscectomy [61]. Exercise exacerbates OA } \\
\text { changes after meniscectomy [62, 63]. Meniscal allograft reduces cartilage damage [65]. }\end{array}$ \\
\hline & $\begin{array}{l}\text { Single traumatic event can lead to OA [69]. Short-term immobilization has minimal effects on joint health, but } \\
\text { long-term immobilization reduces bone mineral density [154-156]. Chondrocyte implantation feasible in single } \\
\text { surgery [157]. }\end{array}$ \\
\hline
\end{tabular}

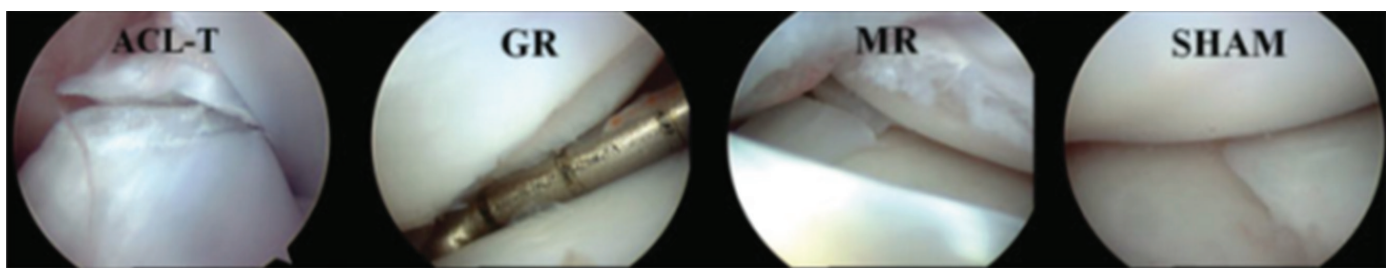

(a)

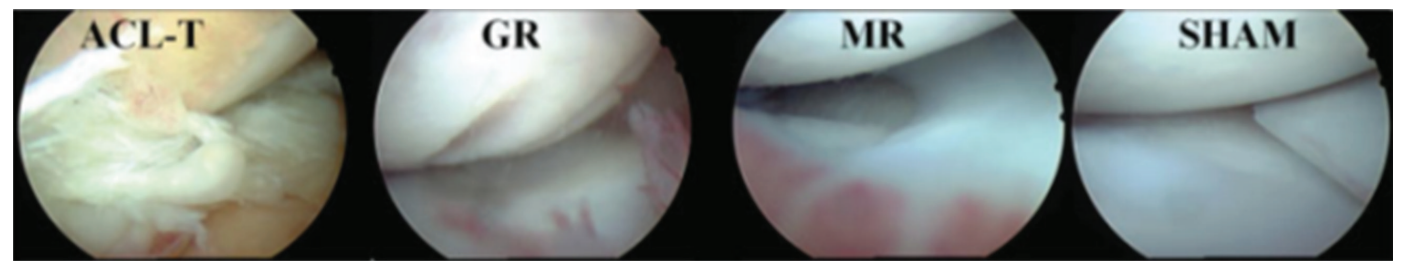

(b)

FIGURE 3: (a, b) Initial and 12-week postoperative arthroscopic views of one dog from each surgical induction model. ACL-T, anterior cruciate ligament transection; GR, groove model; MR, meniscal release; SHAM, manipulation without insult reprinted with permission from $[46]$.

has made finding effective treatments for joint pathology extremely valuable. It follows that much of the equine research has been devoted to that applicable to athletics. Bolam et al. demonstrated that a single traumatic event can lead to osteoarthritis by arthroscopically inducing impact injuries to the articular surface of the medial femoral condyle [69]. Studies have indicated that short-term immobilization has minimal effects on joint health [154], but 7 weeks of immobilization led to reduced range of motion, reduced bone mineral density, and increased lameness even after 8 weeks of increasing exercise $[155,156]$. Frisbie et al. found that several synovial fluid biomarkers and six serum biomarkers were elevated in an osteochondral fragment-exercise model compared to exercise alone [70]. Auer et al. examined the efficacy of hyaluronic acid using experimentally induced OA and spontaneous OA [67]. Other therapies such as triamcinolone acetonide $[71,72]$ and betamethasone [68] have been also tested in equine models. Recently, new technologies have been evaluated in horses. Frisbie et al. demonstrated the feasibility and efficacy of using an adenoviral vector to express interleukin 1 antagonist in the joints of horses with osteoarthritis [73]. The same lab demonstrated the repair of cartilage defects using chondrocyte implantation using only a single procedure [157].

\section{Conclusion}

Knee osteoarthritis remains a tremendous public health concern, both in terms of health-related quality of life and financial burden of disease. Translational animal research plays a critical role in helping to understand the mechanism of disease, to improve methods of early detection, and to 
identify and investigate potential treatment targets. The choice of a particular animal model is multifactorial. Smaller animals are easier to use and less costly, but the information gathered may be less applicable to human OA. Larger animals offer the advantages of spontaneous or readily inducible $\mathrm{OA}$, non or minimally invasive evaluation techniques (i.e., arthroscopy, MRI, and biomarkers) without the need for immediate sacrifice, and closer similarity to human knees. Disadvantages include cost and public perception. Each model has contributed to our understanding of OA (Table 2). Future translational animal models will focus on complete elucidation of disease pathogenesis, determining early markers of disease, and ultimately developing disease-modifying therapy for knee OA.

\section{References}

[1] R. C. Lawrence, D. T. Felson, C. G. Helmick et al., "Estimates of the prevalence of arthritis and other rheumatic conditions in the United States. Part II," Arthritis \& Rheumatism, vol. 58, no. 1, pp. 26-35, 2008.

[2] E. Losina, T. S. Thornhill, B. N. Rome et al., "The dramatic increase in total knee replacement utilization rates in the United States cannot be fully explained by growth in population size and the obesity epidemic," The Journal of Bone \& Joint Surgery A, vol. 94, no. 3, pp. 201-207, 2012.

[3] A. Winterpacht, M. Hilbert, U. Sehwarze, S. Mundlos, J. Spranger, and B. U. Zabel, "Kniest and stickler dysplasia phenotypes caused by collagen type II gene (COL2A1) defect," Nature Genetics, vol. 3, no. 4, pp. 323-326, 1993.

[4] K. Nakata, K. Ono, J. I. Miyazaki et al., "Osteoarthritis associated with mild chondrodysplasia in transgenic mice expressing $\alpha 1$ (IX) collagen chains with a central deletion," Proceedings of the National Academy of Sciences of the United States of America, vol. 90, no. 7, pp. 2870-2874, 1993.

[5] R. Fässler, P. N. J. Schnegelsberg, J. Dausman et al., "Mice lacking $\alpha 1$ (IX) collagen develop noninflammatory degenerative joint disease," Proceedings of the National Academy of Sciences of the United States of America, vol. 91, no. 11, pp. 5070-5074, 1994.

[6] H. J. Helminen, K. Kiraly, A. Pelttari et al., "An inbred line of transgenic mice expressing an internally deleted gene for type II procollagen (COL2A1): young mice have a variable phenotype of a chondrodysplasia and older mice have osteoarthritic changes in joints," The Journal of Clinical Investigation, vol. 92, no. 2, pp. 582-595, 1993.

[7] M. Daans, F. P. Luyten, and R. J. U. Lories, "GDF5 deficiency in mice is associated with instability-driven joint damage, gait and subchondral bone changes," Annals of the Rheumatic Diseases, vol. 70, no. 1, pp. 208-213, 2011.

[8] V. M. Baragi, G. Becher, A. M. Bendele et al., "A new class of potent matrix metalloproteinase 13 inhibitors for potential treatment of osteoarthritis: evidence of histologic and clinical efficacy without musculoskeletal toxicity in rat models," Arthritis \& Rheumatism, vol. 60, no. 7, pp. 2008-2018, 2009.

[9] S. E. Bove, K. D. Laemont, R. M. Brooker et al., "Surgically induced osteoarthritis in the rat results in the development of both osteoarthritis-like joint pain and secondary hyperalgesia," Osteoarthritis and Cartilage, vol. 14, no. 10, pp. 10411048, 2006.

[10] J. Fernihough, C. Gentry, M. Malcangio et al., "Pain related behaviour in two models of osteoarthritis in the rat knee," Pain, vol. 112, no. 1-2, pp. 83-93, 2004.
[11] K. A. Abbud Lozoya and J. B. Kouri Flores, "A novel rat osteoarthrosis model to assess apoptosis and matrix degradation," Pathology, vol. 196, no. 11, pp. 729-745, 2000.

[12] T. Hayami, M. Pickarski, G. A. Wesolowski et al., "The role of subchondral bone remodeling in osteoarthritis: reduction of cartilage degeneration and prevention of osteophyte formation by alendronate in the rat anterior cruciate ligament transection model," Arthritis \& Rheumatism, vol. 50, no. 4, pp. 1193-1206, 2004.

[13] T. Hayami, M. Pickarski, Y. Zhuo, G. A. Wesolowski, G. A. Rodan, and L. T. Duong, "Characterization of articular cartilage and subchondral bone changes in the rat anterior cruciate ligament transection and meniscectomized models of osteoarthritis," Bone, vol. 38, no. 2, pp. 234-243, 2006.

[14] J. M. Williams, D. L. Felten, R. G. Peterson, and B. L. O'Connor, "Effect of surgically induced instability on rat knee articular cartilage," Journal of Anatomy, vol. 134, part 1, pp. 103-109, 1982.

[15] M. Yorimitsu, K. Nishida, A. Shimizu et al., "Intra-articular injection of interleukin-4 decreases nitric oxide production by chondrocytes and ameliorates subsequent destruction of cartilage in instability-induced osteoarthritis in rat knee joints," Osteoarthritis and Cartilage, vol. 16, no. 7, pp. 764771, 2008.

[16] M. J. Janusz, E. B. Hookfin, S. A. Heitmeyer et al., "Moderation of iodoacetate-induced experimental osteoarthritis in rats by matrix metalloproteinase inhibitors," Osteoarthritis and Cartilage, vol. 9, no. 8, pp. 751-760, 2001.

[17] R. E. Guzman, M. G. Evans, S. Bove, B. Morenko, and K. Kilgore, "Mono-iodoacetate-induced histologic changes in subchondral bone and articular cartilage of rat femorotibial joints: an animal model of osteoarthritis," Toxicologic Pathology, vol. 31, no. 6, pp. 619-624, 2003.

[18] M. Bouchgua, K. Alexander, M. André d'Anjou et al., "Use of routine clinical multimodality imaging in a rabbit model of osteoarthritis-part I," Osteoarthritis and Cartilage, vol. 17, no. 2, pp. 188-196, 2009.

[19] L. Díaz-Gallego, J. G. Prieto, P. Coronel, L. E. Gamazo, M. Gimeno, and A. I. Alvarez, "Apoptosis and nitric oxide in an experimental model of osteoarthritis in rabbit after hyaluronic acid treatment," Journal of Orthopaedic Research, vol. 23, no. 6, pp. 1370-1376, 2005.

[20] D. J. S. Hulmes, M. E. Marsden, R. K. Strachan, R. E. Harvey, N. Mclnnes, and D. L. Gardner, "Intra-articular hyaluronate in experimental rabbit osteoarthritis can prevent changes in cartilage proteoglycan content," Osteoarthritis and Cartilage, vol. 12, no. 3, pp. 232-238, 2004.

[21] C. Muehleman, J. Green, J. M. Williams, K. E. Kuettner, E. M. Thonar, and D. R. Sumner, "The effect of bone remodeling inhibition by zoledronic acid in an animal model of cartilage matrix damage," Osteoarthritis and Cartilage, vol. 10, no. 3, pp. 226-233, 2002.

[22] T. Kikuchi, T. Sakuta, and T. Yamaguchi, "Intra-articular injection of collagenase induces experimental osteoarthritis in mature rabbits," Osteoarthritis and Cartilage, vol. 6, no. 3, pp. 177-186, 1998.

[23] E. de Bri, W. Lei, O. Svensson, M. Chowdhury, S. A. Moak, and R. A. Greenwald, "Effect of an inhibitor of matrix metalloproteinases on spontaneous osteoarthritis in guinea pigs," Advances in Dental Research, vol. 12, no. 2, pp. 82-85, 1998.

[24] P. J. Watson, T. A. Carpenter, L. D. Hall, and J. A. Tyler, "MR protocols for imaging the guinea pig knee," Magnetic Resonance Imaging, vol. 15, no. 8, pp. 957-970, 1997. 
[25] J. J. Tessier, J. Bowyer, N. J. Brownrigg et al., "Characterisation of the guinea pig model of osteoarthritis by in vivo threedimensional magnetic resonance imaging," Osteoarthritis and Cartilage, vol. 11, no. 12, pp. 845-853, 2003.

[26] N. Schuelert, M. P. Johnson, J. L. Oskins, K. Jassal, M. G. Chambers, and J. J. McDougall, "Local application of the endocannabinoid hydrolysis inhibitor URB597 reduces nociception in spontaneous and chemically induced models of osteoarthritis," Pain, vol. 152, no. 5, pp. 975-981, 2011.

[27] A. M. Bendele and J. F. Hulman, "Spontaneous cartilage degeneration in guinea pigs," Arthritis \& Rheumatism, vol. 31, no. 4 , pp. 561-565, 1988.

[28] J. L. Huebner, M. A. Hanes, B. Beekman, J. M. TeKoppele, and V. B. Kraus, "A comparative analysis of bone and cartilage metabolism in two strains of guinea-pig with varying degrees of naturally occurring osteoarthritis," Osteoarthritis and Cartilage, vol. 10, no. 10, pp. 758-767, 2002.

[29] K. S. Santangelo, E. M. Pieczarka, G. J. Nuovo, S. E. Weisbrode, and A. L. Bertone, "Temporal expression and tissue distribution of interleukin- $1 \beta$ in two strains of guinea pigs with varying propensity for spontaneous knee osteoarthritis," Osteoarthritis and Cartilage, vol. 19, no. 4, pp. 439-448, 2011.

[30] S. Wang, L. Arsenault, and E. Hunziker, "Stereologic analysis of tibial-plateau cartilage and femoral cancellous bone in guinea pigs with spontaneous osteoarthritis," Clinical Orthopaedics and Related Research, vol. 469, no. 10, pp. 27962805, 2011.

[31] R. D. Young, A. Vaughan-Thomas, R. J. Wardale, and V. C. Duance, "Type II collagen deposition in cruciate ligament precedes osteoarthritis in the guinea pig knee," Osteoarthritis and Cartilage, vol. 10, no. 5, pp. 420-428, 2002.

[32] R. D. Kapadia, A. M. Badger, J. M. Levin et al., "Meniscal ossification in spontaneous osteoarthritis in the guinea-pig," Osteoarthritis and Cartilage, vol. 8, no. 5, pp. 374-377, 2000.

[33] J. Thomsen, T. S. Straarup, C. C. Danielsen et al., "Relationship between articular cartilage damage and subchondral bone properties and meniscal ossification in the Dunkin Hartley guinea pig model of osteoarthritis," Scandinavian Journal of Rheumatology, vol. 40, no. 5, pp. 391-399., 2011.

[34] L. Wei, O. Svensson, and A. Hjerpe, "Correlation of morphologic and biochemical changes in the natural history of spontaneous osteoarthrosis in guinea pigs," Arthritis \& Rheumatism, vol. 40, no. 11, pp. 2075-2083, 1997.

[35] B. Han, A. A. Cole, Y. Shen, T. Brodie, and J. M. Williams, "Early alterations in the collagen meshwork and lesions in the ankles are associated with spontaneous osteoarthritis in guinea-pigs," Osteoarthritis and Cartilage, vol. 10, no. 10, pp. 778-784, 2002.

[36] M. C. Fenty, G. R. Dodge, V. B. Kassey et al., "Quantitative cartilage degeneration associated with spontaneous osteoarthritis in a guinea pig model," Journal of Magnetic Resonance Imaging, vol. 35, no. 4, pp. 891-898, 2012.

[37] J. A. Tyler, P. J. Watson, H. L. Koh, N. J. Herrod, M. Robson, and L. D. Hall, "Detection and monitoring of progressive degeneration of osteoarthritic cartilage by MRI," Acta Orthopaedica Scandinavica, vol. 266, pp. 130-138, 1995.

[38] P. J. Watson, L. D. Hall, A. Malcolm, and J. A. Tyler, "Degenerative joint disease in the guinea pig: use of magnetic resonance imaging to monitor progression of bone pathology," Arthritis \& Rheumatism, vol. 39, no. 8, pp. 1327-1337, 1996.

[39] S. Taniguchi, J. Ryu, M. Seki et al., "Long-term oral administration of glucosamine or chondroitin sulfate reduces destruction of cartilage and up-regulation of MMP-3 mRNA in a model of spontaneous osteoarthritis in Hartley guinea pigs," Journal of Orthopaedic Research, vol. 30, no. 5, pp. 673678, 2012.

[40] K. S. Santangelo and A. L. Bertone, "Effective reduction of the interleukin- $1 \beta$ transcript in osteoarthritis-prone guinea pig chondrocytes via short hairpin RNA mediated RNA interference influences gene expression of mediators implicated in disease pathogenesis," Osteoarthritis and Cartilage, vol. 19, no. 12, pp. 1449-1457, 2011.

[41] T. Ikeda, T. Kubo, Y. Arai et al., "Adenovirus mediated gene delivery to the joints of guinea pigs," The Journal of Rheumatology, vol. 25, no. 9, pp. 1666-1673, 1998.

[42] M. Sato, K. Uchida, H. Nakajima et al., "Direct transplantation of mesenchymal stem cells into the knee joints of Hartley strain guinea pigs with spontaneous osteoarthritis," Arthritis Research \& Therapy, vol. 14, no. 1, article R31, 2012.

[43] A. M. Bendele, "Progressive chronic osteoarthritis in femorotibial joints of partial medial meniscectomized guinea pigs," Veterinary Pathology, vol. 24, no. 5, pp. 444-448, 1987.

[44] J. M. Williams and K. D. Brandt, "Benoxaprofen reduces osteophyte formation and fibrillation after articular cartilage injury," The Journal of Rheumatology, vol. 12, no. 1, pp. 2732, 1985.

[45] S. Kopp, C. Mejersjo, and E. Clemensson, "Induction of osteoarthrosis in the guinea pig knee by papain," Oral Surgery, Oral Medicine and Oral Pathology, vol. 55, no. 3, pp. 259-266, 1983.

[46] B. C. Garner, A. M. Stoker, K. Kuroki et al., "Using animal models in osteoarthritis biomarker research," The Journal of Knee Surgery, vol. 24, no. 4, pp. 251-264, 2011.

[47] M. J. Pond and G. Nuki, "Experimentally-induced osteoarthritis in the dog," Annals of the Rheumatic Diseases, vol. 32, no. 4, pp. 387-388, 1973.

[48] K. Kuroki, C. R. Cook, and J. L. Cook, "Subchondral bone changes in three different canine models of osteoarthritis," Osteoarthritis and Cartilage, vol. 19, no. 9, pp. 1142-1149, 2011.

[49] G. N. Smith, E. A. Mickler, M. E. Albrecht, S. L. Myers, and K. D. Brandt, "Severity of medical meniscus damage in the canine knee after anterior cruciate ligament transection," Osteoarthritis and Cartilage, vol. 10, no. 4, pp. 321-326, 2002.

[50] S. L. Myers, K. D. Brandt, B. L. O’Connor, D. M. Visco, and M. E. Albrecht, "Synovitis and osteoarthritic changes in canine articular cartilage after anterior cruciate ligament transection: effect of surgical hemostasis," Arthritis \& Rheumatism, vol. 33, no. 9, pp. 1406-1415, 1990.

[51] J. A. Vilensky, B. L. O’Connor, K. D. Brandt, E. A. Dunn, P. I. Rogers, and C. A. DeLong, "Serial kinematic analysis of the unstable knee after transection of the anterior cruciate ligament: temporal and angular changes in a canine model of osteoarthritis," Journal of Orthopaedic Research, vol. 12, no. 2, pp. 229-237, 1994.

[52] W. Liu, N. Burton-Wurster, T. T. Glant et al., "Spontaneous and experimental osteoarthritis in dog: similarities and differences in proteoglycan levels," Journal of Orthopaedic Research, vol. 21, no. 4, pp. 730-737, 2003.

[53] D. V. Jovanovic, J. C. Fernandes, J. Martel-Pelletier et al., "In vivo dual inhibition of cyclooxygenase and lipoxygenase by ML-3000 reduces the progression of experimental osteoarthritis: suppression of collagenase 1 and interleukin$1 \beta$ synthesis," Arthritis \& Rheumatism, vol. 44, no. 10, pp. 2320-2330, 2001.

[54] J.-P. Pelletier, C. Boileau, M. Boily et al., "The protective effect of licofelone on experimental osteoarthritis is correlated 
with the downregulation of gene expression and protein synthesis of several major cartilage catabolic factors: MMP13, cathepsin K and aggrecanases," Arthritis Research \& Therapy, vol. 7, no. 5, pp. R1091-R1102, 2005.

[55] J.-P. Pelletier, C. Boileau, J. Brunet et al., "The inhibition of subchondral bone resorption in the early phase of experimental dog osteoarthritis by licofelone is associated with a reduction in the synthesis of MMP-13 and cathepsin K," Bone, vol. 34, no. 3, pp. 527-538, 2004.

[56] M. Moreau, C. Boileau, J. Martel-Pelletier, J. Brunet, S. Laufer, and J. P. Pelletier, "Licofelone reduces progression of structural changes in a canine model of osteoarthritis under curative conditions: effect on protease expression and activity," The Journal of Rheumatology, vol. 33, no. 6, pp. 11761183, 2006.

[57] J. K. Luther, C. R. Cook, and J. L. Cook, "Meniscal release in cruciate ligament intact stifles causes lameness and medial compartment cartilage pathology in dogs 12 weeks postoperatively," Veterinary Surgery, vol. 38, no. 4, pp. 520-529, 2009.

[58] L. N. Frost-Christensen, S. C. Mastbergen, M. E. Vianen et al., "Degeneration, inflammation, regeneration, and pain/disability in dogs following destabilization or articular cartilage grooving of the stifle joint," Osteoarthritis and Cartilage, vol. 16, no. 11, pp. 1327-1335, 2008.

[59] A. C. A. Marijnissen, P. M. van Roermund, J. M. TeKoppele, J. W. J. Bijlsma, and F. P. J. G. Lafeber, "The canine 'groove' model, compared with the ACLT model of osteoarthritis," Osteoarthritis and Cartilage, vol. 10, no. 2, pp. 145-155, 2002.

[60] A. C. A. Marijnissen, P. M. van Roermund, N. Verzijl, J. M. Tekoppele, J. W. J. Bijlsma, and F. P. J. G. Lafeber, "Steady progression of osteoarthritic features in the canine groove model," Osteoarthritis and Cartilage, vol. 10, no. 4, pp. 282289, 2002.

[61] D. I. Bylski-Austrow, J. Malumed, T. Meade, and E. S. Grood, "Knee joint contact pressure decreases after chronic meniscectomy relative to the acutely meniscectomized joint: a mechanical study in the goat," Journal of Orthopaedic Research, vol. 11, no. 6, pp. 796-804, 1993.

[62] P. Ghosh, J. Sutherland, C. Bellenger, R. Read, and A. Darvodelsky, "The influence of weight-bearing exercise on articular cartilage of meniscectomized joints. An experimental study in sheep," Clinical Orthopaedics and Related Research, vol. 252, pp. 101-113, 1990.

[63] S. J. Armstrong, R. A. Read, P. Ghosh, and D. M. Wilson, "Moderate exercise exacerbates the osteoarthritic lesions produced in cartilage by meniscectomy: a morphological study," Osteoarthritis and Cartilage, vol. 1, no. 2, pp. 89-96, 1993.

[64] J. E. Beveridge, N. G. Shrive, and C. B. Frank, "Meniscectomy causes significant in vivo kinematic changes and mechanically induced focal chondral lesions in a sheep model," Journal of Orthopaedic Research, vol. 29, no. 9, pp. 1397-1405, 2011.

[65] B. T. Kelly, H. G. Potter, X. H. Deng et al., "Meniscal allograft transplantation in the sheep knee," The American Journal of Sports Medicine, vol. 34, no. 9, pp. 1464-1477, 2006.

[66] J. M. Murphy, D. J. Fink, E. B. Hunziker, and F. P. Barry, "Stem cell therapy in a caprine model of osteoarthritis," Arthritis \& Rheumatism, vol. 48, no. 12, pp. 3464-3474, 2003.

[67] J. A. Auer, G. E. Fackelman, D. A. Gingerich, and A. W. Fetter, "Effect of hyaluronic acid in naturally occurring and experimentally induced osteoarthritis," American Journal of Veterinary Research, vol. 41, no. 4, pp. 568-574, 1980.
[68] J. W. Foland, C. W. McIlwraith, G. W. Trotter, B. E. Powers, and C. H. Lamar, "Effect of betamethasone and exercise on equine carpal joints with osteochondral fragments," Veterinary Surgery, vol. 23, no. 5, pp. 369-376, 1994.

[69] C. J. Bolam, M. B. Hurtig, A. Cruz, and B. J. E. McEwen, "Characterization of experimentally induced post-traumatic osteoarthritis in the medial femorotibial joint of horses," American Journal of Veterinary Research, vol. 67, no. 3, pp. 433-447, 2006.

[70] D. D. Frisbie, F. Al-Sobayil, R. C. Billinghurst, C. E. Kawcak, and C. W. McIlwraith, "Changes in synovial fluid and serum biomarkers with exercise and early osteoarthritis in horses," Osteoarthritis and Cartilage, vol. 16, no. 10, pp. 1196-1204, 2008.

[71] D. D. Frisbie, C. E. Kawcak, G. W. Trotter, B. E. Powers, R. M. Walton, and C. W. McIlwraith, "Effects of triamcinolone acetonide on an in vivo equine osteochondral fragment exercise model," Equine Veterinary Journal, vol. 29, no. 5, pp. 349-359, 1997.

[72] C. E. Kawcak, R. W. Norrdin, D. D. Frisbie, G. W. Trotter, and C. W. Mcilwraith, "Effects of osteochondral fragmentation and intra-articular triamcinolone acetonide treatment on subchondral bone in the equine carpus," Equine Veterinary Journal, vol. 30, no. 1, pp. 66-71, 1998.

[73] D. D. Frisbie, S. C. Ghivizzani, P. D. Robbins, C. H. Evans, and C. W. McIlwraith, "Treatment of experimental equine osteoarthritis by in vivo delivery of the equine interleukin1 receptor antagonist gene," Gene Therapy, vol. 9, no. 1, pp. 12-20, 2002.

[74] T. Aigner, J. L. Cook, N. Gerwin et al., "Histopathology atlas of animal model systems-overview of guiding principles," Osteoarthritis and Cartilage, vol. 18, supplement 3, pp. S2S6, 2010.

[75] J. L. Cook, K. Kuroki, D. Visco, J. P. Pelletier, L. Schulz, and F. P. J. G. Lafeber, "The OARSI histopathology initiativerecommendations for histological assessments of osteoarthritis in the dog," Osteoarthritis and Cartilage, vol. 18, supplement 3, pp. S66-S79, 2010.

[76] N. Gerwin, A. M. Bendele, S. Glasson, and C. S. Carlson, "The OARSI histopathology initiative-recommendations for histological assessments of osteoarthritis in the rat," Osteoarthritis and Cartilage, vol. 18, supplement 3, pp. S24S34, 2010.

[77] S. S. Glasson, M. G. Chambers, W. B. van den Berg, and C. B. Little, "The OARSI histopathology initiative-recommendations for histological assessments of osteoarthritis in the mouse," Osteoarthritis and Cartilage, vol. 18, supplement 3, pp. S17-S23, 2010.

[78] V. B. Kraus, J. L. Huebner, J. DeGroot, and A. Bendele, "The OARSI histopathology initiative-recommendations for histological assessments of osteoarthritis in the guinea pig," Osteoarthritis and Cartilage, vol. 18, supplement 3, pp. S35S52, 2010.

[79] S. Laverty, C. A. Girard, J. M. Williams, E. B. Hunziker, and K. P. H. Pritzker, "The OARSI histopathology initiativerecommendations for histological assessments of osteoarthritis in the rabbit," Osteoarthritis and Cartilage, vol. 18, supplement 3, pp. S53-S65, 2010.

[80] C. B. Little, M. M. Smith, M. A. Cake, R. A. Read, M. J. Murphy, and F. P. Barry, "The OARSI histopathology initiative-recommendations for histological assessments of osteoarthritis in sheep and goats," Osteoarthritis and Cartilage, vol. 18, supplement 3, pp. S80-S92, 2010. 
[81] C. W. McIlwraith, D. D. Frisbie, C. E. Kawcak, C. J. Fuller, M. Hurtig, and A. Cruz, "The OARSI histopathology initiative-recommendations for histological assessments of osteoarthritis in the horse," Osteoarthritis and Cartilage, vol. 18, supplement 3, pp. S93-S105, 2010.

[82] A. M. Bendele, "Animal models of osteoarthritis," Journal of Musculoskeletal and Neuronal Interactions, vol. 1, no. 4, pp. 363-376, 2001.

[83] C. B. Little and M. M. Smith, "Animal models of osteoarthritis," Current Rheumatology Reviews, vol. 4, no. 3, pp. 175-182, 2008.

[84] R. Poole, S. Blake, M. Buschmann et al., "Recommendations for the use of preclinical models in the study and treatment of osteoarthritis," Osteoarthritis and Cartilage, vol. 18, supplement 3, pp. S10-S16, 2010.

[85] G. Smale, A. Bendele, and W. E. Horton Jr., "Comparison of age-associated degeneration of articular cartilage in Wistar and Fischer 344 rats," Laboratory Animal Science, vol. 45, no. 2, pp. 191-194, 1995.

[86] M. Tirgari and L. C. Vaughan, "Arthritis of the canine stifle joint," Veterinary Record, vol. 96, no. 18, pp. 394-399, 1975.

[87] G. Nilsson and S. E. Olsson, "Radiologic and patho-anatomic changes in the distal joints and the phalanges of the standardbred horse," Acta Veterinaria Scandinavica, vol. 44, pp. 1-57, 1973.

[88] D. T. Felson, Y. Zhang, M. T. Hannan et al., "The incidence and natural history of knee osteoarthritis in the elderly: the Framingham osteoarthritis study," Arthritis \& Rheumatism, vol. 38, no. 10, pp. 1500-1505, 1995.

[89] A. C. Gelber, M. C. Hochberg, L. A. Mead, N. Y. Wang, F. M. Wigley, and M. J. Klag, "Joint injury in young adults and risk for subsequent knee and hip osteoarthritis," Annals of Internal Medicine, vol. 133, no. 5, pp. 321-328, 2000.

[90] R. G. Johnson, "Transection of the canine anterior cruciate ligament: a concise review of experience with this model of degenerative joint disease," Experimental Pathology, vol. 30, no. 4, pp. 209-213, 1986.

[91] C. McDevitt, E. Gilbertson, and H. Muir, "An experimental model of osteoarthritis; early morphological and biochemical changes," Journal of Bone \& Joint Surgery B, vol. 59, no. 1, pp. 24-35, 1977.

[92] M. Libicher, M. Ivancic, V. Hoffmann, and W. Wenz, "Early changes in experimental osteoarthritis using the Pond-Nuki dog model: technical procedure and initial results of in vivo MR imaging," European Radiology, vol. 15, no. 2, pp. 390 394, 2005.

[93] M.-A. D’Anjou, M. Moreau, É. Troncy et al., “Osteophytosis, subchondral bone sclerosis, joint effusion and soft tissue thickening in canine experimental stifle osteoarthritis: comparison between 1.5 T magnetic resonance imaging and computed radiography," Veterinary Surgery, vol. 37, no. 2, pp. 166-177, 2008.

[94] S. C. Mastbergen, A. C. Marijnissen, M. E. Vianen, P. M. van Roermund, J. W. Bijlsma, and F. P. Lafeber, "The canine 'groove' model of osteoarthritis is more than simply the expression of surgically applied damage," Osteoarthritis and Cartilage, vol. 14, no. 1, pp. 39-46, 2006.

[95] Y. H. Sniekers, H. Weinans, S. M. Bierma-Zeinstra, J. P. T. M. van Leeuwen, and G. J. V. M. van Osch, "Animal models for osteoarthritis: the effect of ovariectomy and estrogen treatment-a systematic approach," Osteoarthritis and Cartilage, vol. 16, no. 5, pp. 533-541, 2008.
[96] A. M. Bendele and J. F. Hulman, "Effects of body weight restriction on the development and progression of spontaneous osteoarthritis in guinea pigs," Arthritis \& Rheumatism, vol. 34, no. 9, pp. 1180-1184, 1991.

[97] M. M. Hyttinen, J. P. A. Arokoski, J. J. Parkkinen et al., "Age matters: collagen birefringence of superficial articular cartilage is increased in young guinea-pigs but decreased in older animals after identical physiological type of joint loading," Osteoarthritis and Cartilage, vol. 9, no. 8, pp. 694-701, 2001.

[98] P. Krzeski, C. Buckland-Wright, G. Bálint et al., "Development of musculoskeletal toxicity without clear benefit after administration of PG-116800, a matrix metalloproteinase inhibitor, to patients with knee osteoarthritis: a randomized, 12-month, double-blind, placebo-controlled study," Arthritis Research \& Therapy, vol. 9, no. 5, article R109, 2007.

[99] C. O. Bingham, J. C. Buckland-Wright, P. Garnero et al., "Risedronate decreases biochemical markers of cartilage degradation but does not decrease symptoms or slow radiographic progression in patients with medial compartment osteoarthritis of the knee: results of the two-year multinational knee osteoarthritis structural arthritis study," Arthritis \& Rheumatism, vol. 54, no. 11, pp. 3494-3507, 2006.

[100] L. P. Yu, G. N. Smith, K. D. Brandt, S. L. Myers, B. L. O'Connor, and D. A. Brandt, "Reduction of the severity of canine osteoarthritis by prophylactic treatment with oral doxycycline," Arthritis \& Rheumatism, vol. 35, no. 10, pp. 1150-1159, 1992.

[101] F. Eckstein and W. Wirth, "Quantitative cartilage imaging in knee osteoarthritis," Arthritis, vol. 2011, Article ID 475684, 19 pages, 2011.

[102] F. W. Roemer, M. D. Crema, S. Trattnig, and A. Guermazi, "Advances in imaging of osteoarthritis and cartilage," Radiology, vol. 260, no. 2, pp. 332-354, 2011.

[103] C. Boileau, J. Martel-Pelletier, F. Abram et al., "Magnetic resonance imaging can accurately assess the long-term progression of knee structural changes in experimental dog osteoarthritis," Annals of the Rheumatic Diseases, vol. 67, no. 7, pp. 926-932, 2008.

[104] J.-P. Raynauld, J. Martel-Pelletier, P. Bias et al., "Protective effects of licofelone, a 5-lipoxygenase and cyclo-oxygenase inhibitor, versus naproxen on cartilage loss in knee osteoarthritis: a first multicentre clinical trial using quantitative MRI," Annals of the Rheumatic Diseases, vol. 68, no. 6, pp. 938-947, 2009.

[105] Y. Wang, S. Hall, F. Hanna et al., "Effects of Hylan G-F 20 supplementation on cartilage preservation detected by magnetic resonance imaging in osteoarthritis of the knee: a two-year single-blind clinical trial," BMC Musculoskeletal Disorders, vol. 12, no. 1, article 195, 2011.

[106] T. E. McAlindon, M. Nuite, N. Krishnan et al., "Change in knee osteoarthritis cartilage detected by delayed gadolinium enhanced magnetic resonance imaging following treatment with collagen hydrolysate: a pilot randomized controlled trial," Osteoarthritis and Cartilage, vol. 19, no. 4, pp. 399-405, 2011.

[107] D. Laurent, E. O’Byrne, J. Wasvary, and T. C. Pellas, "In vivo MRI of cartilage pathogenesis in surgical models of osteoarthritis," Skeletal Radiology, vol. 35, no. 8, pp. 555-564, 2006.

[108] C. E. Kawcak, D. D. Frisbie, N. M. Werpy, R. D. Park, and C. W. Mcllwraith, "Effects of exercise vs experimental osteoarthritis on imaging outcomes," Osteoarthritis and Cartilage, vol. 16, no. 12, pp. 1519-1525, 2008. 
[109] J. M. Blair-Levy, C. E. Watts, N. M. Fiorientino, E. K. Dimitriadis, J. C. Marini, and P. E. Lipsky, "A type I collagen defect leads to rapidly progressive osteoarthritis in a mouse model," Arthritis \& Rheumatism, vol. 58, no. 4, pp. 10961106, 2008.

[110] J. C. Goebel, R. Bolbos, M. Pham et al., "High-resolution MRI (7T) of femoro-tibial cartilage changes in the rat anterior cruciate ligament transection model of osteoarthritis: a cross-sectional study," Rheumatology, vol. 49, no. 9, pp. 1654$1664,2010$.

[111] E. L. Dubois, R. E. Horowitz, H. B. Demopoulos, and R. Teplitz, "NZB/NZW mice as a model of systemic lupus erythematosus," The Journal of the American Medical Association, vol. 195, no. 4, pp. 285-289, 1966.

[112] W. H. Simon, "Scale effects in animal joints. I. Articular cartilage thickness and compressive stress," Arthritis \& Rheumatism, vol. 13, no. 3, pp. 244-256, 1970.

[113] S. S. Glasson, T. J. Blanchet, and E. A. Morris, "The surgical destabilization of the medial meniscus (DMM) model of osteoarthritis in the $129 / \mathrm{SvEv}$ mouse," Osteoarthritis and Cartilage, vol. 15, no. 9, pp. 1061-1069, 2007.

[114] K. Chapman, A. Takahashi, I. Meulenbelt et al., "A metaanalysis of European and Asian cohorts reveals a global role of a functional SNP in the 5' UTR of GDF5 with osteoarthritis susceptibility," Human Molecular Genetics, vol. 17, no. 10, pp. 1497-1504, 2008.

[115] L. Southam, J. Rodriguez-Lopez, J. M. Wilkins et al., "An SNP in the 5'-UTR of GDF5 is associated with osteoarthritis susceptibility in Europeans and with in vivo differences in allelic expression in articular cartilage," Human Molecular Genetics, vol. 16, no. 18, pp. 2226-2232, 2007.

[116] Y. Miyamoto, A. Mabuchi, D. Shi et al., "A functional polymorphism in the $5^{\prime}$ UTR of GDF5 is associated with susceptibility to osteoarthritis," Nature Genetics, vol. 39, no. 4, pp. 529-533, 2007.

[117] K. Gelse, K. Von der Mark, T. Aigner, J. Park, and H. Schneider, "Articular cartilage repair by gene therapy using growth factor-producing mesenchymal cells," Arthritis \& Rheumatism, vol. 48, no. 2, pp. 430-441, 2003.

[118] R. Kuroda, A. Usas, S. Kubo et al., "Cartilage repair using bone morphogenetic protein 4 and muscle-derived stem cells," Arthritis \& Rheumatism, vol. 54, no. 2, pp. 433-442, 2006.

[119] T. Nishida, S. Kubota, S. Kojima et al., "Regeneration of defects in articular cartilage in rat knee joints by CCN2 (connective tissue growth factor)," Journal of Bone and Mineral Research, vol. 19, no. 8, pp. 1308-1319, 2004.

[120] M. Cowart, G. Hsieh, L. A. Black et al., "Pharmacological characterization of A-960656, a histamine $\mathrm{H}_{3}$ receptor antagonist with efficacy in animal models of osteoarthritis and neuropathic pain," European Journal of Pharmacology, vol. 684, no. 1-3, pp. 87-94, 2012.

[121] A. S. Ahmed, J. Li, H. Erlandsson-Harris et al., "Suppression of pain and joint destruction by inhibition of the proteasome system in experimental osteoarthritis," PAIN, vol. 153, no. 1, pp. 18-26, 2012.

[122] A. Chevrier, M. Nelea, M. B. Hurtig, C. D. Hoemann, and M. D. Buschmann, "Meniscus structure in human, sheep, and rabbit for animal models of meniscus repair," Journal of Orthopaedic Research, vol. 27, no. 9, pp. 1197-1203, 2009.

[123] X. Wei, J. Gao, and K. Messner, "Maturation-dependent repair of untreated osteochondral defects in the rabbit knee joint," Journal of Biomedical Materials Research, vol. 34, no. 1, pp. 63-72, 1997.
[124] M. Kaweblum, M. Del Carmen Aguilar, E. Blancas et al., "Histological and radiographic determination of the age of physeal closure of the distal femur, proximal tibia, and proximal fibula of the New Zealand white rabbit," Journal of Orthopaedic Research, vol. 12, no. 5, pp. 747-749, 1994.

[125] C. Boulocher, E. Chereul, J. B. Langlois et al., "Noninvasive in vivo quantification of the medial tibial cartilage thickness progression in an osteoarthritis rabbit model with quantitative 3D high resolution micro-MRI," Osteoarthritis and Cartilage, vol. 15, no. 12, pp. 1378-1387, 2007.

[126] T. Yoshimi, T. Kikuchi, T. Obara et al., "Effects of highmolecular-weight sodium hyaluronate on experimental osteoarthrosis induced by the resection of rabbit anterior cruciate ligament," Clinical Orthopaedics and Related Research, vol. 298, pp. 296-304, 1994.

[127] C. Shimizu, T. Kubo, Y. Hirasawa, R. D. Coutts, and D. Amiel, "Histomorphometric and biochemical effect of various hyaluronans on early osteoarthritis," The Journal of Rheumatology, vol. 25, no. 9, pp. 1813-1819, 1998.

[128] K. Takahashi, R. S. Goomer, F. Harwood, T. Kubo, Y. Hirasawa, and D. Amiel, "The effects of hyaluronan on matrix metalloproteinase-3 (MMP-3), interleukin-1 $\beta$ (IL-1 $\beta$ ), and tissue inhibitor of metalloproteinase-1 (TIMP-1) gene expression during the development of osteoarthritis," Osteoarthritis and Cartilage, vol. 7, no. 2, pp. 182-190, 1999.

[129] Q. Zhang, A. Chen, F. Liu et al., "Efficacy of infliximab in a rabbit model of osteoarthritis," Connective Tissue Research, vol. 53, no. 5, pp. 355-358, 2012.

[130] D. D’Lima, J. Hermida, S. Hashimoto, C. Colwell, and M. Lotz, "Caspase inhibitors reduce severity of cartilage lesions in experimental osteoarthritis," Arthritis \& Rheumatism, vol. 54, no. 6, pp. 1814-1821, 2006.

[131] W. Hongbin, D. Jingyuan, C. Linyun, and D. Yuming, "Carboxymethylated chitin reduces MMP-1 expression in rabbit ACLT osteoarthritic cartilage," Annals of the Rheumatic Diseases, vol. 63, no. 4, pp. 369-372, 2004.

[132] S.-Q. Liu, B. Qiu, L. Y. Chen, H. Peng, and Y. M. Du, “The effects of carboxymethylated chitosan on metalloproteinase$1,-3$ and tissue inhibitor of metalloproteinase- 1 gene expression in cartilage of experimental osteoarthritis," Rheumatology International, vol. 26, no. 1, pp. 52-57, 2005.

[133] N. Elmali, I. Esenkaya, A. Harma, K. Ertem, Y. Turkoz, and B. Mizrak, "Effect of resveratrol in experimental osteoarthritis in rabbits," Inflammation Research, vol. 54, no. 4, pp. 158162, 2005.

[134] M. R. Doschak, J. M. LaMothe, D. M. L. Cooper et al., "Bisphosphonates reduce bone mineral loss at ligament entheses after joint injury," Osteoarthritis and Cartilage, vol. 13, no. 9, pp. 790-797, 2005.

[135] M. R. Doschak, G. R. Wohl, D. A. Hanley, R. C. Bray, and R. F. Zernicke, "Antiresorptive therapy conserves some periarticular bone and ligament mechanical properties after anterior cruciate ligament disruption in the rabbit knee," Journal of Orthopaedic Research, vol. 22, no. 5, pp. 942-948, 2004.

[136] A. M. Bendele, S. L. White, and J. F. Hulman, "Osteoarthrosis in guinea pigs: histopathologic and scanning electron microscopic features," Laboratory Animal Science, vol. 39, no. 2, pp. 115-121, 1989.

[137] P. A. Jimenez, S. S. Glasson, O. V. Trubetskoy, and H. B. Haimes, "Spontaneous osteoarthritis in Dunkin Hartley guinea pigs: histologic, radiologic, and biochemical changes," Laboratory Animal Science, vol. 47, no. 6, pp. 598-601, 1997. 
[138] D. C. Brown, R. C. Boston, J. C. Coyne, and J. T. Farrar, "Ability of the canine brief pain inventory to detect response to treatment in dogs with osteoarthritis," Journal of the American Veterinary Medical Association, vol. 233, no. 8, pp. 1278-1283, 2008.

[139] B. L. O'Connor, D. M. Visco, D. A. Heck, S. L. Myers, and K. D. Brandt, "Gait alterations in dogs after transection of the anterior cruciate ligament," Arthritis \& Rheumatism, vol. 32, no. 9, pp. 1142-1147, 1989.

[140] K. Lindblad-Toh, C. M. Wade, T. S. Mikkelsen et al., "Genome sequence, comparative analysis and haplotype structure of the domestic dog," Nature, vol. 438, no. 7069, pp. 803-819, 2005.

[141] K. D. Rainsford, T. M. Skerry, P. Chindemi, and K. Delaney, "Effects of the NSAIDs meloxicam and indomethacin on cartilage proteoglycan synthesis and joint responses to calcium pyrophosphate crystals in dogs," Veterinary Research Communications, vol. 23, no. 2, pp. 101-113, 1999.

[142] M. M. D. Scheck and L. Sakovich, "Degenerative joint disease of the canine hip: experimental production by multiple papain and prednisone injections," Clinical Orthopaedics and Related Research, vol. 86, pp. 115-120, 1972.

[143] S. A. Johnston, "Osteoarthritis. Joint anatomy, physiology, and pathobiology," The Veterinary Clinics of North America, vol. 27, no. 4, pp. 699-723, 1997.

[144] R. O. Sanderson, C. Beata, R. M. Flipo et al., "Systematic review of the management of canine osteoarthritis," Veterinary Record, vol. 164, no. 14, pp. 418-424, 2009.

[145] J. L. Cook and J. T. Payne, "Surgical treatment of osteoarthritis," The Veterinary Clinics of North America, vol. 27, no. 4, pp. 931-944, 1997.

[146] R. C. Billinghurst, L. Dahlberg, M. Ionescu et al., "Enhanced cleavage of type II collagen by collagenases in osteoarthritic articular cartilage," The Journal of Clinical Investigation, vol. 99, no. 7, pp. 1534-1545, 1997.

[147] B. V. Shlopov, W. R. Lie, C. L. Mainardi, A. A. Cole, S. Chubinskaya, and K. A. Hasty, "Osteoarthritic lesions: involvement of three different collagenases," Arthritis \& Rheumatism, vol. 40, no. 11, pp. 2065-2074, 1997.

[148] G.-H. Yuan, K. Masuko-Hongo, M. Sakata et al., "The role of C-C chemokines and their receptors in osteoarthritis," Arthritis \& Rheumatism, vol. 44, no. 5, pp. 1056-1070, 2001.

[149] S. P. Oakley, I. Portek, Z. Szomor et al., "Arthroscopy-a potential "gold standard" for the diagnosis of the chondropathy of early osteoarthritis," Osteoarthritis and Cartilage, vol. 13 , no. 5, pp. 368-378, 2005.

[150] A. M. Rørvik and J. Teige, "Unstable stifles without clinical or radiographic osteoarthritis in young goats: an experimental study," Acta Veterinaria Scandinavica, vol. 37, no. 3, pp. 265272, 1996.

[151] S. Heiligenstein, M. Cucchiarini, M. W. Laschke et al., "Evaluation of nonbiomedical and biomedical grade alginates for the transplantation of genetically modified articular chondrocytes to cartilage defects in a large animal model in vivo," The Journal of Gene Medicine, vol. 13, no. 4, pp. 230242, 2011.

[152] B. Marquass, R. Schulz, P. Hepp et al., "Matrix-associated implantation of predifferentiated mesenchymal stem cells versus articular chondrocytes," The American Journal of Sports Medicine, vol. 39, no. 7, pp. 1401-1412, 2011.

[153] Y. Lu, S. Dhanaraj, Z. Wang et al., "Minced cartilage without cell culture serves as an effective intraoperative cell source for cartilage repair," Journal of Orthopaedic Research, vol. 24, no. 6, pp. 1261-1270, 2006.

[154] D. W. Richardson and C. C. Clark, "Effects of short-term cast immobilization on equine articular cartilage," American Journal of Veterinary Research, vol. 54, no. 3, pp. 449-453, 1993.

[155] P. D. van Harreveld, J. D. Lillich, C. E. Kawcak, E. M. Gaughan, R. M. McLaughlin, and R. M. DeBowes, "Clinical evaluation of the effects of immobilization followed by remobilization and exercise on the metacarpophalangeal joint in horses," American Journal of Veterinary Research, vol. 63, no. 2, pp. 282-288, 2002.

[156] P. D. van Harreveld, J. D. Lillich, C. E. Kawcak, A. S. Turner, and R. W. Norrdin, "Effects of immobilization followed by remobilization on mineral density, histomorphometric features, and formation of the bones of the metacarpophalangeal joint in horses," American Journal of Veterinary Research, vol. 63, no. 2, pp. 276-281, 2002.

[157] D. D. Frisbie, Y. Lu, C. E. Kawcak, E. F. DiCarlo, F. Binette, and C. W. McIlwraith, "In vivo evaluation of autologous cartilage fragment-loaded scaffolds implanted into equine articular defects and compared with autologous chondrocyte implantation," The American Journal of Sports Medicine, vol. 37, no. 1, supplement, pp. 71S-80S, 2009. 


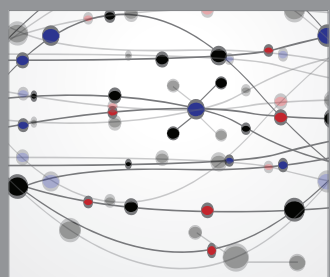

The Scientific World Journal
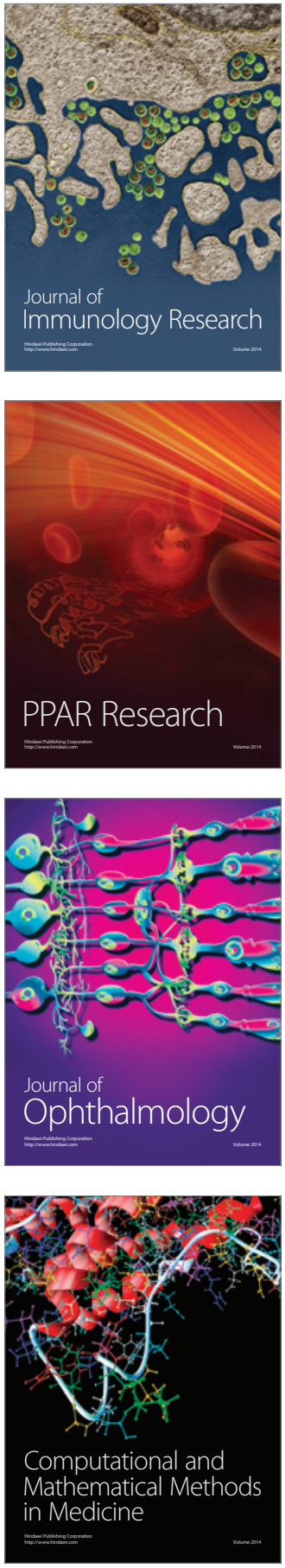

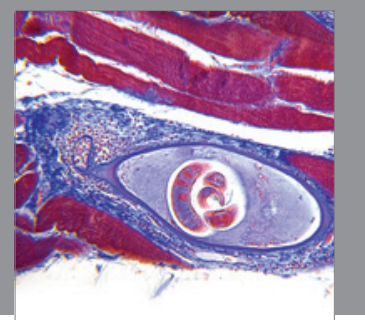

Gastroenterology

Research and Practice
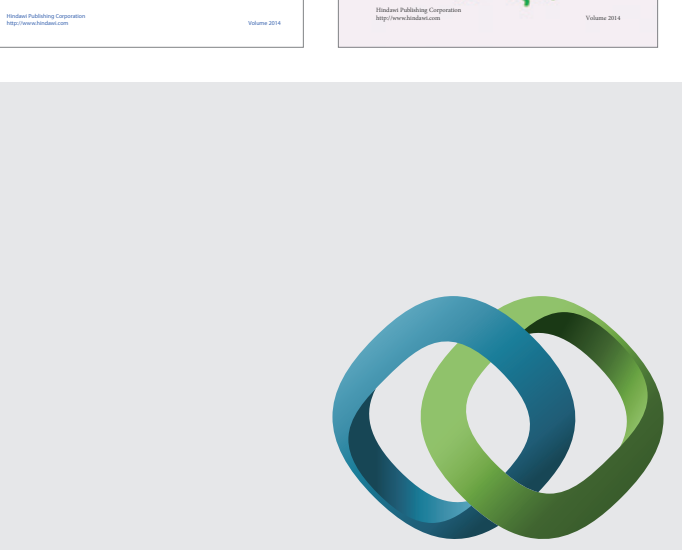

\section{Hindawi}

Submit your manuscripts at

http://www.hindawi.com
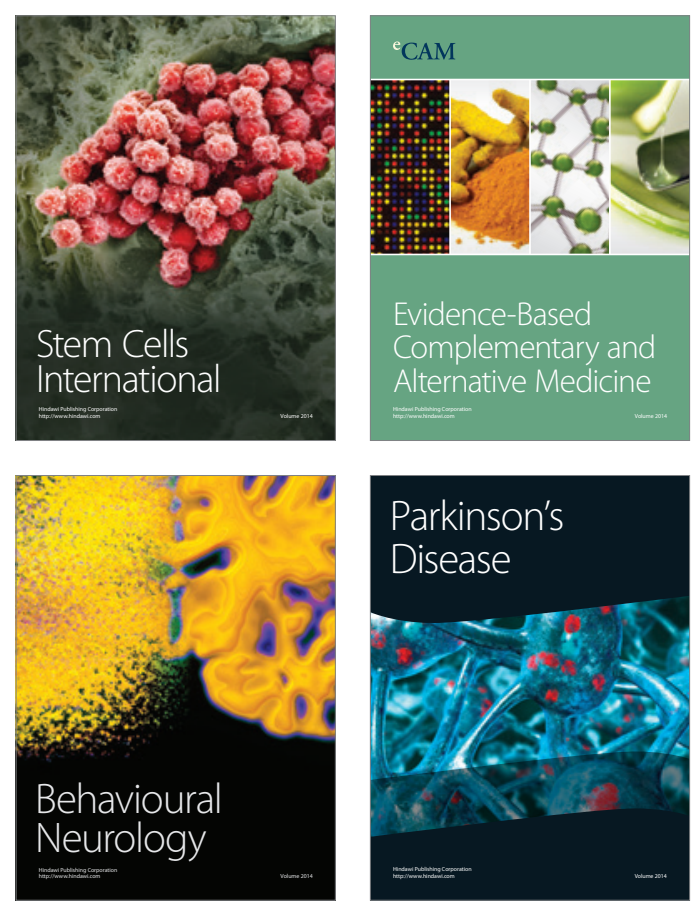

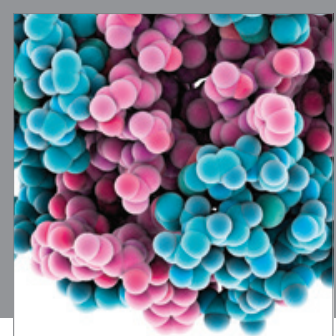

Journal of
Diabetes Research

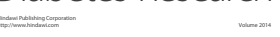

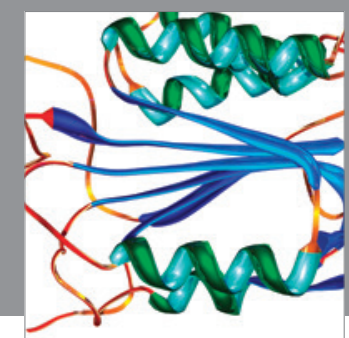

Disease Markers
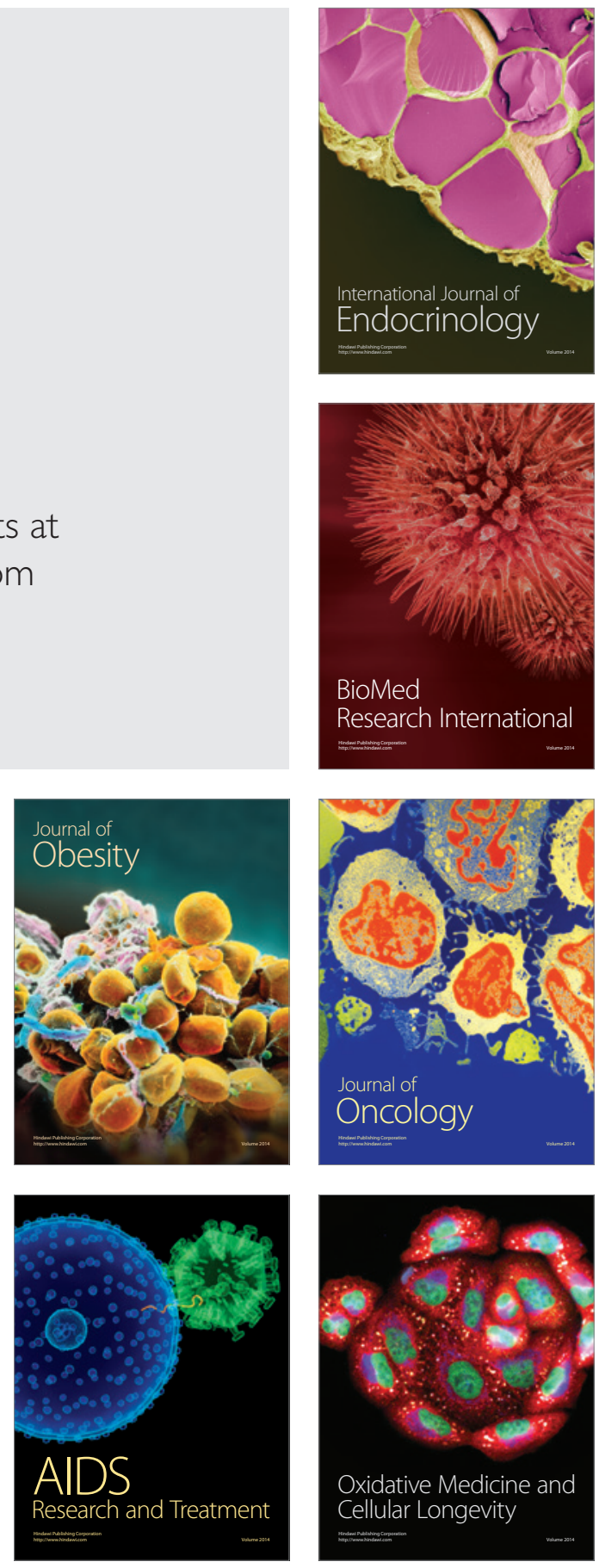